Ciência Florestal, Santa Maria, v. 26, n. 1, p. 235-247, jan.-mar., 2016

ISSN 0103-9954

\title{
MULTIPLICAÇÃO E ALONGAMENTO IN VITRO DE CLONES HÍBRIDOS DE Eucalyptus globulus
}

\section{IN VITRO MULTIPLICATION AND ELONGATION OF HYBRID CLONES OF Eucalyptus globulus}

\author{
Leandro Silva de Oliveira ${ }^{1}$ Aloisio Xavier ${ }^{2}$ Aline Pontes Lopes ${ }^{3}$ Elizabete Keiko Takahashi ${ }^{4}$ \\ Wagner Campos Otoni ${ }^{5}$
}

\begin{abstract}
RESUMO
Os híbridos de Eucalyptus globulus representam uma excelente alternativa para o setor de celulose e papel, em razão dos ganhos em qualidade da madeira para a fabricação de celulose. Entretanto, estes híbridos têm apresentado recalcitrância ao enraizamento adventício. Assim, a micropropagação é apontada como a técnica para o rejuvenescimento desses híbridos adultos, viabilizando a propagação clonal dos mesmos. $\mathrm{O}$ presente trabalho avaliou o cultivo in vitro de três clones de Eucalyptus grandis x Eucalyptus globulus e de três clones de Eucalyptus urophylla x Eucalyptus globulus, em relação à multiplicação in vitro, no meio MS suplementado com 0,5 mg L-1 de BAP e $0,01 \mathrm{mg} \mathrm{L}^{-1}$ de ANA, bem como o efeito das concentrações de 0,$25 ; 0,50 ; 0,75$ e $1,0 \mathrm{mg} \mathrm{L}^{-1}$ de AIB e dos meios de cultura MS e JADS no alongamento in vitro das brotações. Os clones diferiram quanto à multiplicação in vitro das brotações e apresentaram uma taxa de multiplicação média dos clones de 3,0 tufos de brotações em cada subcultivo, ao longo dos 25 subcultivos realizados. No alongamento in vitro, os clones diferiram quanto às concentrações de AIB adequadas para provocar o alongamento, bem como em relação aos meios de cultura MS e JADS. O intervalo médio entre 0,40 e $0,80 \mathrm{mg} \mathrm{L}^{-1}$ de AIB proporcionou o maior número e comprimento das brotações alongadas in vitro e com maior vigor.
\end{abstract}

Palavras-chave: rejuvenescimento; regulador de crescimento; meio de cultura; subcultivo.

\section{ABSTRACT}

Eucalyptus globulus hybrids represent an excellent alternative to the pulp and paper sector, because of gains in wood quality for pulp. However, these hybrids have shown recalcitrance to adventitious rooting. Thus, micropropagation is considered the technique for rejuvenating adult genetic materials, allowing its clonal propagation. This study evaluated the in vitro culture of three clones of Eucalyptus grandis $\mathrm{x}$ Eucalyptus globulus and three clones of Eucalyptus urophylla $\mathrm{x}$ Eucalyptus globulus in relation to in vitro multiplication on MS medium supplemented with $0.5 \mathrm{mgL}^{-1} \mathrm{BAP}$ and $0,01 \mathrm{mgL}^{-1} \mathrm{NAA}$. The effect of IBA concentrations $\left(0.25 ; 0.50 ; 0.75\right.$ and $\left.1.0 \mathrm{mg} \mathrm{L}^{-1}\right)$ and MS and JADS culture media was evaluated on in vitro elongation. The clones differed during in vitro multiplication of shoots and they had an average multiplication rate of 3.0 shoot clusters in each subculture. The responses of the clones to different concentrations of IBA, as well as to MS and JADS culture media differed for elongation in vitro. The range between 0.40 and $0.80 \mathrm{mg} \mathrm{L}^{-1}$

1 Engenheiro Florestal, Dr., Pós-Doutorando no Programa de Pós-Graduação em Ciências Florestais e Ambientais, Faculdade de Engenharia Florestal da Universidade Federal do Mato Grosso, Av. Fernando Correa da Costa, s/n, Coxipó da Ponte, CEP 78060-900, Cuiabá (MT), Brasil. leandroengflor@gmail.com

2 Engenheiro Florestal, Dr., Professor Adjunto do Departamento de Engenharia Florestal, Universidade Federal de Viçosa, Av. Ph. Rolfs, s/n, CEP 36571-000, Viçosa (MG), Brasil. xavier@ufv.br

3 Engenheira Florestal, Mestranda no Programa de Pós-Graduação em Ciências de Florestas Tropicais do Instituto Nacional de Pesquisas da Amazônia, Av. André Araújo, 2936, Petrópolis, CEP 69060-001, Manaus (AM), Brasil. alineplopes@gmail.com.br

4 Bióloga, Dr ${ }^{\mathrm{a}}$., Pesquisadora Celulose Nipo-Brasileira S/A., Rodovia de Ligação BR 381 a Belo Oriente Km 3, Caixa Postal 100, CEP 35196-972, Belo Oriente (MG), Brasil. elizabete.takahashi@cenibra.com.br

5 Engenheiro Agrônomo, Dr., Professor Associado, Departamento de Biologia Vegetal, Universidade Federal de Viçosa, Av. Ph. Rolfs, s/n, CEP 36571-000, Viçosa (MG), Brasil. wotoni@ufv.br

Recebido para publicação em 19/09/2011 e aceito em 5/06/2014

Ci. Fl., v. 26, n. 1, jan.-mar., 2016 
AIB provided the highest number and length of in vitro elongated shoots and the best vigor of shoots. Keywords: rejuvenation; growth regulator; culture medium; subculture.

\section{INTRODUÇÃO}

No Brasil, a hibridação do Eucalyptus globulus com outras espécies desse gênero tem gerado excelentes resultados, tanto nas características de qualidade da madeira quanto no crescimento (BORGES et al., 2011). Entretanto, a clonagem em larga escala destes híbridos, pela técnica de miniestaquia, não tem alcançado resultados satisfatórios quanto ao enraizamento, por se tratar de uma espécie considerada recalcitrante, apresentando índices inferiores aos desejados na produção de mudas clonais (OLIVEIRA et al., 2012).

$\mathrm{Na}$ busca por alternativas para o rejuvenescimento de clones selecionados, e consequentemente a melhoria do enraizamento adventício no processo de produção de mudas clonais de Eucalyptus, a micropropagação via proliferação de gemas axilares tem sido recomendada como técnica alcançar esse objetivo (GOMES; CANHOTO, 2003; BRONDANI et al., 2012). Dessa forma, a micropropagação apresentase como uma ferramenta de grande utilidade no setor florestal, em razão de possibilitar a formação e manutenção de microjardins clonais, a partir de clones rejuvenescidos, permitindo a propagação de genótipos de interesse.

Para Eucalyptus, a micropropagação com fins de rejuvenescimento é dependente do número de subcultivos in vitro, dos meios de cultura e do balanço hormonal necessários para alcançar melhores respostas quanto ao potencial de enraizamento adventício. Em geral, para o rejuvenescimento de clones de Eucalyptus spp. selecionados na idade adulta, recomenda-se no mínimo 12 subcultivos (DUTRA et al., 2009). Contudo, esse rejuvenescimento é progressivo e parcial, bem como dependente da espécie e idade ontogenética do material vegetativo utilizado na micropropagação (XAVIER; WENDLING; SILVA, 2009).

De maneira geral, uma resposta positiva à micropropagação, dentre diversos fatores, deve-se a um balanço adequado dos reguladores de crescimento, sendo os mais utilizados, as citocininas e as auxinas (XAVIER; WENDLING;
SILVA, 2009). As concentrações desses reguladores de crescimento variam de acordo com o estágio de micropropagação e em função da espécie e do tipo de explante (GRATTAPAGLIA; MACHADO, 1998). $\mathrm{Na}$ micropropagação de espécies de Eucalyptus, diversos trabalhos de cultivo in vitro têm utilizado a citocinina 6-benzilaminopurina (BAP) e as auxinas ácido $\alpha$-naftalenoacético (ANA), ácido indolil-3acético (AIA) e o ácido indol-3-butírico (AIB) nas formulações de meios de cultura para multiplicação e alongamento (BENNETT et al., 1994; DEL PONTE et al., 2001).

Com relação ao meio de cultura, o meio MS (MURASHIGE; SKOOG, 1962) tem sido um dos mais utilizados na micropropagação de Eucalyptus e seus híbridos (SHARMA; RAMAMURTHY, 2000; NUGENT et al., 2001; BILLARD; LALLANA, 2005; GLOCKE; COLLINS; SEDGLEY, 2006; AGGARWAL et al., 2012). No entanto, outros meios de cultura, como JADS (CORREIA et al., 1995), também têm sido empregados. O meio de cultura JADS foi elaborado especificamente para Eucalyptus grandis, sendo também utilizado na micropropagação de outras espécies do gênero (LIMA; GONÇALVES, 1998; SANTOS et al., 2004; ANDRADE; ALMEIDA; GONÇALVES, 2006; BRAVO et al., 2008). O meio de cultura B5 (GAMBORG; MILLER; OJIMA, 1968) também foi utilizado na micropropagação de Eucalyptus (GLOCKE et al., 2006; ARYA et al., 2009), bem como o meio de cultura QLP (QUOIRIN; LEPOIVRE, 1977) (SOTELO; MONZA, 2007). O meio de cultura WPM (LLOYD; MCCOWN, 1981) foi utilizado na micropropagação de Eucalyptus benthamii e seus híbridos (BRONDANI et al., 2009; 2012), Eucalyptus polybractea (GOODGER et al., 2008) e Eucalyptus globulus (PINTO et al., 2008).

Dentre as etapas da micropropagação, em virtude da metodologia adotada para a proliferação das gemas axilares, tem uma etapa de multiplicação acompanhada de uma fase de alongamento in vitro, a qual é necessária para a obtenção de brotações com tamanho adequado para a fase de enraizamento destas, a qual tem sido realizada $e x$ vitro (XAVIER; WENDLING; SILVA, 2009) ou in vitro (TRINDADE; PAIS, 1997; BENNETT; MCDAVID; MCCOMB， 2003; NOURISSIER; 
MONTEUUIS, 2008).

Em vista da necessidade de adequação de um protocolo de micropropagação, para clones híbridos de Eucalyptus urophylla x Eucalyptus globulus e Eucalyptus grandis x Eucalyptus globulus, visando o rejuvenescimento e, ou, revigoramento clonal, o presente trabalho teve como objetivos: (i) avaliar o comportamento dos clones durante a multiplicação in vitro ao longo de sucessivos subcultivos e (ii) avaliar o alongamento dos clones cultivados em meios contendo diferentes concentrações de AIB , bem como nos meios de cultura MS e JADS.

\section{MATERIAL E MÉTODOS}

\section{Material experimental}

Os materiais vegetais utilizados nesse trabalho foram provenientes da fase de multiplicação de três clones de Eucalyptus urophylla x Eucalyptus globulus (C01, C04 e C16) e três clones de Eucalyptus grandis x Eucalyptus globulus (C26, C29 e C30), oriundos da empresa Celulose Nipo-Brasileira S.A. (CENIBRA), localizada no município de Belo Oriente, Minas Gerais. Esses clones foram obtidos pela hibridação interespecífica, realizada em programa de melhoramento estabelecido pela empresa, com a utilização de pólen de Eucalyptus globulus, procedente do Instituto Raiz, de Portugal, e como genitores femininos, genótipos superiores de Eucalyptus urophylla e Eucalyptus grandis da própria empresa.

A partir de minicepas estabelecidas em minijardim clonal, sob sistema semi-hidropônico de canaletão de areia, no Viveiro de Pesquisas Florestais do Departamento de Engenharia Florestal da Universidade Federal de Viçosa, coletaramse brotações, contendo um par de gemas, para a introdução in vitro dos referidos clones. $\mathrm{O}$ estabelecimento in vitro foi realizado conforme protocolo descrito por Borges et al. (2011).

\section{Multiplicação in vitro}

Nesta fase, as brotações formadas na fase de estabelecimento in vitro foram inoculadas em tubos de ensaio de $15 \times 2.5 \mathrm{~cm}$, contendo $10 \mathrm{~mL}$ de meio de cultura MS, suplementado com $0,5 \mathrm{mg} \mathrm{L}^{-1}$ de BAP, $0,01 \mathrm{mg} \mathrm{L}^{-1}$ de ANA, $800 \mathrm{mg} \mathrm{L}^{-1}$ de PVP$30,30 \mathrm{~g} \mathrm{~L}^{-1}$ de sacarose e $6 \mathrm{~g} \mathrm{~L}^{-1}$ de ágar.

Realizou-se a transferência das brotações multiplicadas para um novo meio de cultura de igual composição e sob as mesmas condições de cultivo, a cada 30 dias, isolando-se tufos de brotações. Os tufos de brotações foram padronizados como sendo um aglomerado de brotações múltiplas com três a quatro gemas maiores do que $3 \mathrm{~mm}$. A fase de multiplicação in vitro compreendeu a realização de um total de 25 subcultivos sucessivos.

A taxa de multiplicação de cada clone foi determinada ao final de cada subcultivo, dividindo o número de tufos de brotações, obtidas ao final de cada período de 30 dias, pelo número inicial de tufos de brotações do explante proveniente da fase de estabelecimento in vitro. Para tanto os tufos de brotações foram subdivididos ao final de cada subcultivo.

O número de tufos de brotações produzidas por cada clone foi avaliado ao término de cada subcultivo, sendo o experimento conduzido em delineamento inteiramente casualizado, testandose seis clones híbridos de Eucalyptus globulus com 4 repetições compostas cada uma por 5 tubos de ensaio.

\section{Alongamento in vitro}

Os explantes constituídos de tufos de brotações contendo 5 brotações maiores que $3 \mathrm{~mm}$, obtidos na fase de multiplicação, foram inoculados em frascos de 7 x $6 \mathrm{~cm}$ contendo $40 \mathrm{~mL}$ de meio de cultura, MS ou JADS, ambos suplementados com 0,25; 0,50; 0,75 e 1,0 $\mathrm{mg} \mathrm{L}^{-1}$ de AIB e $0,05 \mathrm{mg} \mathrm{L}^{-1} \mathrm{de}$ BAP. Adicionou-se ainda aos meios de cultura 800 $\mathrm{mg} \mathrm{L}{ }^{-1}$ de PVP30 e $6 \mathrm{~g} \mathrm{~L}^{-1}$ de ágar.

$\mathrm{O}$ número de subcultivos realizados na etapa de multiplicação in vitro antes do alongamento variou entre os clones, sendo realizados para os clones $\mathrm{C} 01, \mathrm{C} 04, \mathrm{C} 16, \mathrm{C} 26, \mathrm{C} 29$ e $\mathrm{C} 30$ ao todo 16 , $15,18,14,16$ e 14 subcultivos, respectivamente.

$\mathrm{O}$ vigor, a hiper-hidricidade, a oxidação, o número e comprimento das brotações (gemas axilares maiores que $1,0 \mathrm{~cm}$ ) foram avaliados 35 dias após a inoculação, de acordo com uma escala de notas (Tabela 1). A oxidação das brotações foi avaliada indiretamente por meio da avaliação do escurecimento do meio de cultura.

O delineamento estatístico utilizado para o experimento de alongamento in vitro foi o inteiramente casualizado (DIC) em esquema fatorial $(6 \times 5 \times 2)$, testando-se 6 clones, 5 concentrações de AIB e 2 meios de cultura. Utilizou-se6 explantes por frasco de cultivo, tendo cada tratamento 6 repetições. 
TABELA 1: Escala de notas para a classificação do vigor, da oxidação, da hiperidricidade das brotações no alongamento in vitro dos clones de Eucalyptus urophylla x Eucalyptus globulus (C01, C04 e C16) e Eucalyptus grandis x Eucalyptus globulus (C26, C29 e C30).

TABLE 1: Scoring method for vigor, oxidation and hyperhydricity of shoots of Eucalyptus urophylla $\mathrm{x}$ Eucalyptus globulus (C01, C04 and C16) and Eucalyptus grandis x Eucalyptus globulus (C26, $\mathrm{C} 29$ and $\mathrm{C} 30)$ clones.

\begin{tabular}{cl}
\hline \multicolumn{1}{c}{ Variáveis } & \multicolumn{1}{c}{ Pontuação atribuída / Descrição } \\
\hline Vigor das brotações & 1 - Baixo - senescência e morte das brotaçõs \\
& - Regular - ausência de desenvolvimento das brotações \\
& 3 - Médio - brotações com entrenós curtos (aspecto rosetado), crescimento reduzido \\
& - Bom - brotaçôes com bom crescimento, porém com folhas de tamanho reduzido \\
& 5 - Ótimo - brotações com crescimento ativo, sem deficiência nutricional \\
\hline Hiper-hidricidade & 0 - Nula - sem hiperidricidade \\
das brotações & - Baixa - reduzida hipertrofia dos tecidos foliares \\
& 2 - Média - elevada hipertrofia dos tecidos foliares \\
& 3 - Alta - hipertrofiados tecidos foliares e dos entrenós dos explantes \\
& 4 - Total -hipertrofia de todos os tecidos dos explantes, ocasionando sua morte \\
\hline Oxidação & 0 - Nula - sem oxidação \\
das brotações & 2 - Baixa - reduzida oxidação na base dos explantes \\
& 3 - Média - alta oxidação na base dos explantes \\
& 4 - Total - oxidaçãão completa do meio de cultura (meio de cultura completa do meio de cultura (tom enegrecido) \\
\hline
\end{tabular}

\section{Análise dos dados}

Os dados foram submetidos à análise de variância (ANOVA) $(p<0,05)$, sendo as médias comparadas pelo teste de Tukey $(p<0,05)$ e por regressão polinomial. Utilizaram-se o programa STATISTICA $7.0 \quad\left(\mathrm{STASOFT}^{\circledR}\right)$ para os procedimentos estatísticos e para o ajuste das equações de regressão o programa CURVE EXPERT 1.3.

\section{Condições de cultura}

Os meios de cultura, foram preparados utilizando água desionizada e o $\mathrm{pH}$ ajustado para $5,8 \pm 0,05 \mathrm{com} \mathrm{NaOH}(0,1 \mathrm{M})$ e $\mathrm{HCl}(0,1 \mathrm{M})$, antes da autoclavagem e adição do ágar. A autoclavagem do meio de cultura foi realizada à temperatura de $121^{\circ} \mathrm{C}$ e pressão de aproximadamente $1 \mathrm{kgf} \mathrm{cm}^{-2}$, durante 15 minutos.

Os reguladores de crescimento BAP, ANA e AIB foram adicionados ao meio de cultura antes da autoclavagem. Em todos os experimentos realizados, os explantes foram cultivados em sala de cultura com temperatura de $25 \pm 2{ }^{\circ} \mathrm{C}$, fotoperíodo de 16 horas e irradiância de $40 \mu \mathrm{mol} \mathrm{m} \mathrm{s}^{-1}$, fornecidas por lâmpadas fluorescentes de luz branca-fria.

\section{RESULTADOS E DISCUSSÃO Multiplicação in vitro}

Os resultados demonstraram variação na taxa de multiplicação ao longo dos subcultivos para todos os clones (Figura 1), dificultando distinguir um ponto específico da estabilização desta taxa, na qual não se observa o incremento no número de brotações produzidas. Bennett et al. (1994) afirmam que a duração desse período de estabilização é variável de acordo com a espécie e idade do material de origem.

As variações das respostas nos diferentes subcultivos podem ser resultantes, em parte, das condições de cultivo. De acordo com Mankessi et al. (2009), a exposição excessiva, através de regimes de subcultivos de longo prazo, com inadequadas concentrações dos componentes do meio, pode resultar em elevação das concentrações ideais de determinadas substâncias dentro dos tecidos vegetais, refletindo no desempenho da cultura como na obtenção de baixas taxas de multiplicação. Essa situação é especialmente aplicável ao regulador de crescimento BAP, uma citocinina sintética mais estável e menos suscetível à degradação por oxidases, do que seus homólogos naturais (GEORGE, 2008).

$\mathrm{O}$ incremento do enraizamento das brotações micropropagadas, normalmente é obtido conforme se prolongam os subcultivos, devido ao rejuvenescimento ocorrido nos explantes (TRINDADE; PAIS, 1997). O efeito rejuvenescedor dos sucessivos subcultivos, em meio enriquecido com BAP, já foi relatado para diferentes espécies arbóreas micropropagadas (HACKETT, 1987; 

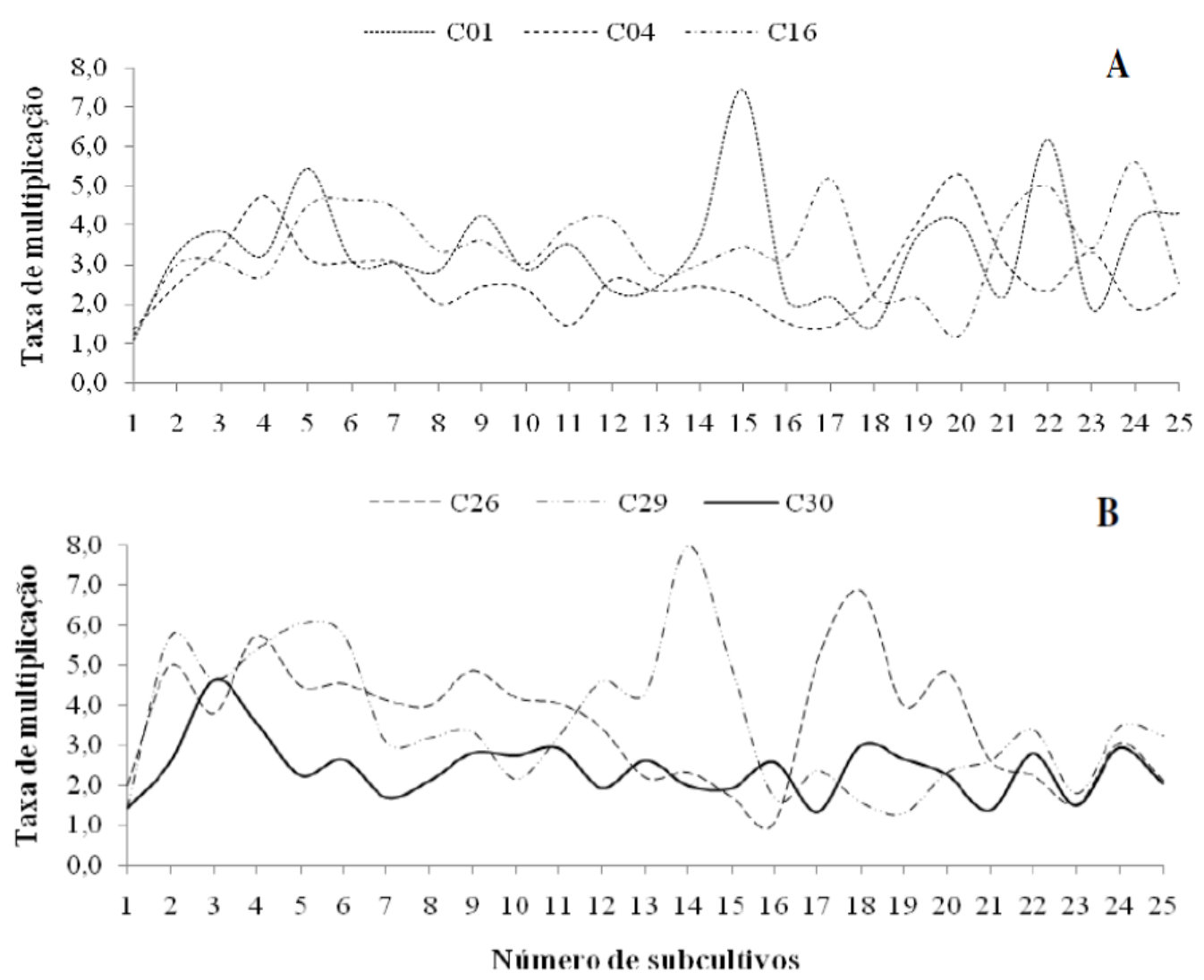

FIGURA 1: Taxa de multiplicação dos clones de Eucalyptus urophylla x Eucalyptus globulus (C01, C04 e C16) e Eucalyptus grandis x Eucalyptus globulus (C26, C29 e C30), na fase de multiplicação in vitro no meio de cultura MS com 0,5 $\mathrm{mg} \mathrm{L}^{-1}$ de BAP e $0,01 \mathrm{mg} \mathrm{L}^{-1}$ de ANA, em 25 subcultivos.

FIGURE 1: Multiplication rate of Eucalyptus urophylla x Eucalyptus globulus (C01, C04 and C16) and Eucalyptus grandis x Eucalyptus globulus (C26, C29 and C30) clones, during the in vitro multiplication stage in MS culture medium supplemented with $0,5 \mathrm{mg} \mathrm{L}^{-1} \mathrm{BAP}$ and $0,01 \mathrm{mg} \mathrm{L}^{-1} \mathrm{NAA}$, during 25 subcultures.

PIERIK, 1990; VON ADERKAS; BONGA, 2000), dentre essas Eucalyptus (WARRAG; LESNEY; ROCKWOOD, 1990; TRINDADE; PAIS, 1997; SHARMA; RAMAMURTHY, 2000; MANKESSI et al., 2009). Contudo o período de tempo necessário para o rejuvenescimento de cada clone tem sido variável. No presente estudo, há indicativo de reversão à juvenilidade dos clones híbridos de Eucalyptus globulus em razão dos valores positivos da taxa de multiplicação in vitro, apesar da sua variação no decorrer dos subcultivos. De acordo com Chalupa (2002), a juvenilidade dos explantes é um fator determinante para a obtenção de elevadas taxas de multiplicação.

Os clones apresentaram diferença significativa quanto à produção média de tufos de brotações ao longo dos subcultivos, sendo obtido o maior número de tufos de brotações para os clones C26 e C29, os quais não diferiram dos clones C01, $\mathrm{C} 04$ eC16(Figura 2). Esse resultado reflete a variação de resposta de diferentes genótipos à multiplicação in vitro. Sotelo e Monza (2007) definiram um protocolo de micropropagação de clones adultos de Eucalyptus globulus sub. maidenii, por meio de gemas epicórmicas, observando que apenas 5 clones de um total de 58 avaliados apresentaram resposta à multiplicação in vitro, evidenciando que o genótipo tem efeito direito nesta variação.

O número médio de tufos de brotações $(2,4 \mathrm{a}$ $3,6)$ produzidos pelos clones híbridos de Eucalyptus globulus foi superior ao valor de 2,25 obtido por Gomes e Canhoto (2003) na proliferação de gemas 


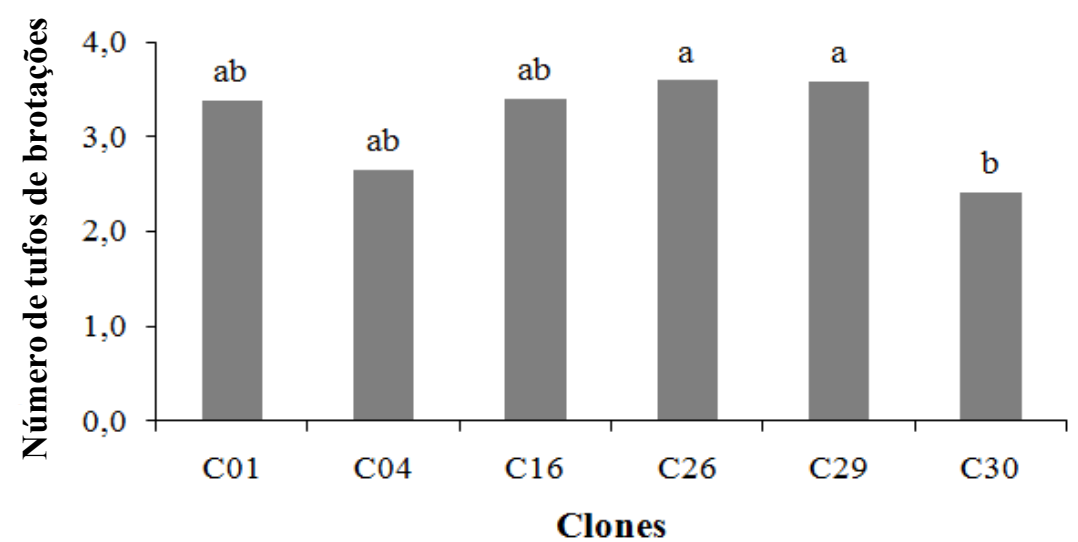

FIGURA 2: Número médio de tufos de brotações (NBF) produzidos por explante em 25 subcultivos pelos clones de Eucalyptus urophylla x Eucalyptus globulus(C01, C04 e C16) e Eucalyptus grandis x Eucalyptus globulus(C26, C29 e C30), na fase de multiplicação in vitro em meio de cultura MS contendo $0,5 \mathrm{mg} \mathrm{L}^{-1}$ de BAP e $0,01 \mathrm{mg} \mathrm{L}^{-1}$ de ANA.

FIGURE 2: Mean number of shoot clusters per explant of 25 subcultures of Eucalyptus urophylla $\mathrm{x}$ Eucalyptus globulus (C01, C04 and C16) and Eucalyptus grandis x Eucalyptus globulus (C26, $\mathrm{C} 29$ and $\mathrm{C} 30$ ) clones, during the multiplication stage in MS culture medium supplemented with $0,5 \mathrm{mg} \mathrm{L}^{-1} \mathrm{BAP}$ and $0,01 \mathrm{mg} \mathrm{L}^{-1} \mathrm{NAA}$.

de Eucalyptus nitens. Não obstante, outros trabalhos utilizando o meio MS suplementado com ANA e BAP apresentaram resultados superiores para a multiplicação in vitro de Eucalyptus tereticornis $\mathrm{x}$ Eucalyptus grandis (JOSHI et al., 2003), Eucalyptus tereticornis (SHARMA; RAMAMURTHY, 2000). No entanto, o número de subcultivos realizados foi muito menor ao realizado no presente estudo (25 subcultivos), não permitindo averiguar se o protocolo de multiplicação seria adequado para o subcultivo prolongado das brotações de Eucalyptus conforme apresentado no presente trabalho.

Em relação aos reguladores de crescimento, nesse estudo a combinação de BAP e ANA adotada permitiu estimular a multiplicação in vitro dos clones avaliados, com o desenvolvimento de brotações com um bom vigor vegetativo. BAP é à citocinina mais utilizada na micropropagação de Eucalyptus spp. (DEL PONTE et al., 2001; ALVES; XAVIER; OTONI, 2004). Para Eucalyptus globulus e seus híbridos, o uso do BAP associado ao ANA foi a melhor combinação para promover a multiplicação das brotações ao longo dos subcultivos realizados (CALDERÓN-BALTIERRA， 1994; GÓMEZ; RÍOS; SÁNCHEZ-OLATE, 2007; BORGES et al., 2011). Entretanto, Sotelo e Monza (2007) obtiveram melhores resultados de multiplicação após 5 subcultivos em meio de cultura suplementado com 0,2 $\mathrm{mg} \mathrm{L}^{-1}$ de BAP e 0,02 $\mathrm{mg} \mathrm{L}^{-1}$ de AIB. Diferentemente, Bennett et al. (1994) conseguiram maior número de brotações de materiais adultos de Eucalyptus globulus ao realizar a alternância do uso de BAP e cinetina nos subcultivos.

De modo geral, as respostas dos clones à multiplicação in vitro mostraram-se satisfatórias, apesar de haver diferenças entre os materiais genéticos. Os resultados obtidos para os clones, possivelmente devem-se a estes materiais serem adultos, uma vez que o grau de maturação dos explante sutilizados tem efeito direto nos resultados obtidos na micropropagação, (SOTELO; MONZA, 2007). Dessa forma, os incrementos na taxas de multiplicação ao longo dos subcultivos indicaram que a multiplicação in vitro mostrou-se eficiente para provocar o seu rejuvenescimento, uma vez que a juvenilidade é um fator determinante para a obtenção de elevadas taxas de multiplicação (CHALUPA, 2002).

\section{Alongamento in vitro}

De acordo com o teste $\mathrm{F}(p<0,05)$ houve interação dos clones em relação ao meio de cultivo e aos tratamentos com AIB para todas as características avaliadas (Tabela 2). Esse resultado indica a diversidade de resposta dos clones em relação ao meio de cultivo e aos tratamentos com 
TABELA 2: Resumo da análise de variância do vigor, oxidação, hiperidricidade e comprimento das brotações, número de brotações alongadas por explante de clones de Eucalyptus urophylla $\mathrm{x}$ Eucalyptus globulus (C01, C04 e C16) e Eucalyptus grandis x Eucalyptus globulus (C26, C29 e C30), aos 35 dias após a inoculação, em função das doses de AIB aplicados aos meios de cultura MS e JADS adicionados de $0,05 \mathrm{mg} \mathrm{L}^{-1}$ de BAP.

TABLE 2: Analyses of variance of the vigor, oxidation, hyperhydricity, shoot length and number of elongated shoots per explant of Eucalyptus urophylla x Eucalyptus globulus (C01, C04 and C16) and Eucalyptus grandis x Eucalyptus globulus (C26, C29 and C30) clones, 35 days after inoculation, in function IBA concentrations applied in MS and JADS culture media, supplemented with $0.05 \mathrm{mg} \mathrm{L}^{-1}$ BAP.

\begin{tabular}{|c|c|c|c|c|c|c|}
\hline \multirow[b]{2}{*}{ Fonte de Variação } & \multirow[b]{2}{*}{ G.L. } & \multicolumn{5}{|c|}{ Quadrados Médios } \\
\hline & & Vigor $^{1}$ & Oxidação $^{1}$ & Hiperidricidade $^{2}$ & $\begin{array}{l}\text { Comprimento } \\
\text { das brotações }\end{array}$ & $\begin{array}{c}\mathrm{N}^{\circ} \text { de } \\
\text { brotações } \\
\text { alongadas }\end{array}$ \\
\hline Clone (C) & 5 & $0,434^{*}$ & $0,888^{*}$ & $1,6167^{*}$ & $6,5781 *$ & $36,543^{*}$ \\
\hline Meios de Cultura (M) & 1 & $0,718^{*}$ & $1,047^{*}$ & $0,4868^{*}$ & $3,5516^{*}$ & $107,803 *$ \\
\hline Tratamentos AIB (T) & 4 & $0,716^{*}$ & $3,160^{*}$ & $0,4204 *$ & $25,0192^{*}$ & $86,053^{*}$ \\
\hline $\mathrm{C} \times \mathrm{M}$ & 5 & $0,140^{*}$ & $0,367^{*}$ & $0,5925^{*}$ & $2,8868^{*}$ & $16,063 *$ \\
\hline $\mathrm{CxT}$ & 20 & $0,069 *$ & $0,109 *$ & $0,0982 *$ & $1,7666^{*}$ & $9,943^{*}$ \\
\hline $\mathrm{M} \times \mathrm{T}$ & 4 & $0,218^{*}$ & $0,214^{*}$ & $0,0675^{*}$ & $7,5587^{*}$ & $25,303 *$ \\
\hline $\mathrm{C} \times \mathrm{M} \times \mathrm{T}$ & 20 & $0,041 *$ & $0,060^{*}$ & $0,0791 *$ & $2,3647^{*}$ & $4,196^{*}$ \\
\hline Resíduo & 300 & 0,017 & 0,019 & 0,0235 & 0,1439 & 0,878 \\
\hline Média Geral & - & 1,780 & 1,680 & 1,430 & 1,130 & 1,810 \\
\hline CV (\%) & - & 7,32 & 8,20 & 10,72 & 33,57 & 51,77 \\
\hline
\end{tabular}

Em que: ${ }^{\text {ns }} \mathrm{F}$ não significativo a 5\% de probabilidade; * F significativo a 5\% de probabilidade. Dados transformados por $\sqrt{x+0,5}$ por $\ln (x+0,5)$ em virtude de não apresentarem normalidade pelo teste de Lilliefors a $5 \%$ de probabilidade. $\mathrm{GL}=$ graus de liberdade, $\mathrm{CV}=$ coeficiente de variação.

AIB, o que reforça o efeito do material genético na propagação vegetativa.

Os clones apresentaram comportamento polinomial de segundo grau para o vigor vegetativo das brotações nos meios MS e JADS (Figura 3). No entanto, no meio MS os valores máximos estimados para o vigor das brotações foram observados nas concentrações de 0,42 a $0,78 \mathrm{mg} \mathrm{L}^{-1}$ de AIB, enquanto no meio JADS, os valores máximos estimados foram observados nas concentrações de AIB superiores a $0,58 \mathrm{mg} \mathrm{L}^{-1}$. Dessa forma, não há uma única concentração ótima de AIB para obter brotações com o máximo de vigor vegetativo para todos os clones nos dois meios de cultura. Salienta-se que, na ausência de AIB, as brotações apresentaram crescimento reduzido, constatando-se muitas vezes a morte de explantes com o decorrer do tempo de subcultivo.

De modo geral, as brotações dos clones cultivados no meio JADS apresentaram vigor vegetativo de médio a bom, considerando os valores máximos estimados para essa variável, exceto apenas o clone $\mathrm{C} 16$, cuja estimativa do vigor das brotações foi de 2,3, considerado regular (Figura 3B). Por outro lado, no meio MS, os valores máximos estimados do vigor das brotações ficaram na classificação de regular a médio (Figura 3A).

Em relação à oxidação das brotações, observou-se o seu acréscimo nas maiores concentrações de AIB testadas no meio JADS, obtendo-se valores máximos estimados acima de $0,69 \mathrm{mg} \mathrm{L}^{-1}$, sendo estas estimativas da oxidação classificadas dentro de uma faixa de alta a total (Figura 4B). Este resultado confirma que as altas concentrações de reguladores de crescimento no meio de cultura são um dos fatores responsáveis pela oxidação das brotações (RIBEIRO et al., 2012).

De maneira geral, a hiper-hidricidade das brotações foi média a baixa para os clones em ambos meios de cultura, com exceção apenas do clone C29 no meio de cultura MS no qual a hiperidricidade foi acima da média (Figura 5A). 

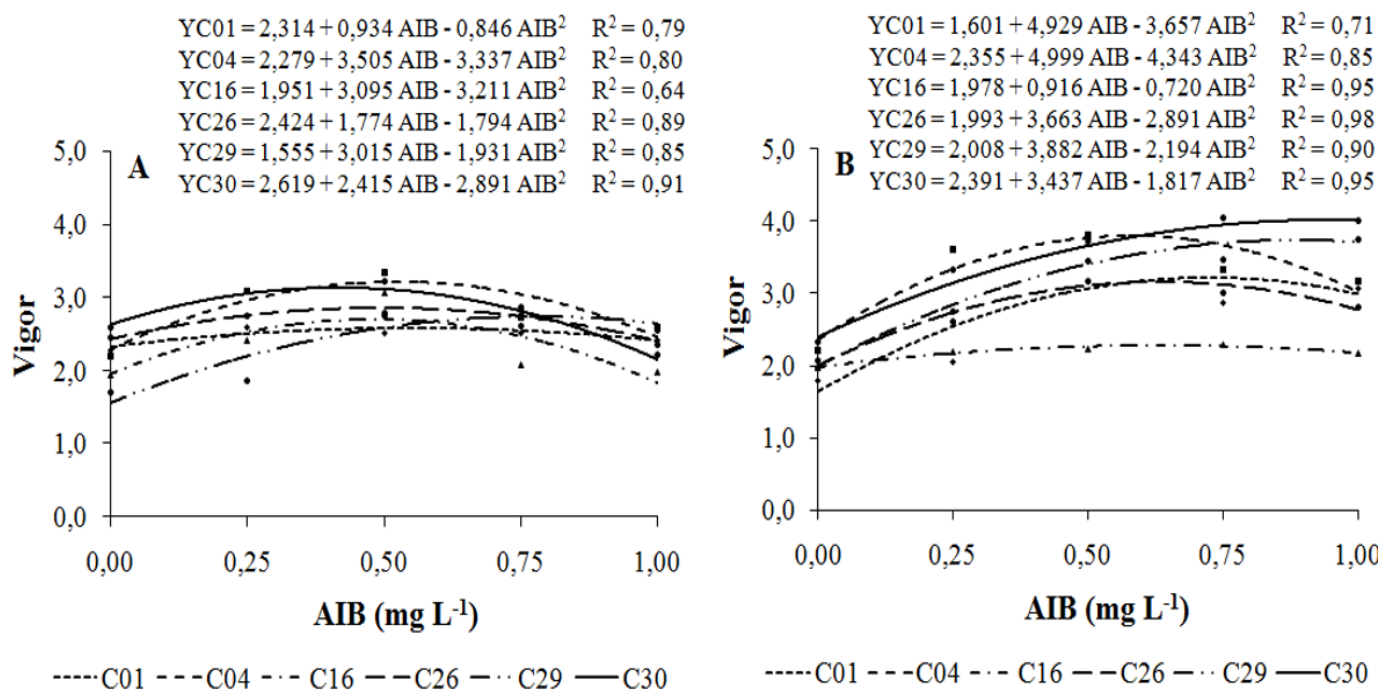

FIGURA 3: Vigor das brotações de Eucalyptus urophylla x Eucalyptus globulus (C01, C04 e C16) e Eucalyptus grandis x Eucalyptus globulus (C26, C29 e C30), aos 35 dias após a inoculação, em função das doses de AIB aplicados aos meios de cultura MS (A) e JADS (B) contendo 0,05 $\mathrm{mg} \mathrm{L}^{-1}$ de BAP.

FIGURE 3: Vigor of shoots of Eucalyptus urophylla x Eucalyptus globulus (C01, C04 and C16) and Eucalyptus grandis x Eucalyptus globulus (C26, C29 and C30) clones, 35 days after inoculation, in function of IBA concentrations applied in MS (A) and JADS (B) culture media supplemented with $0.05 \mathrm{mg} \mathrm{L}^{-1} \mathrm{BAP}$.
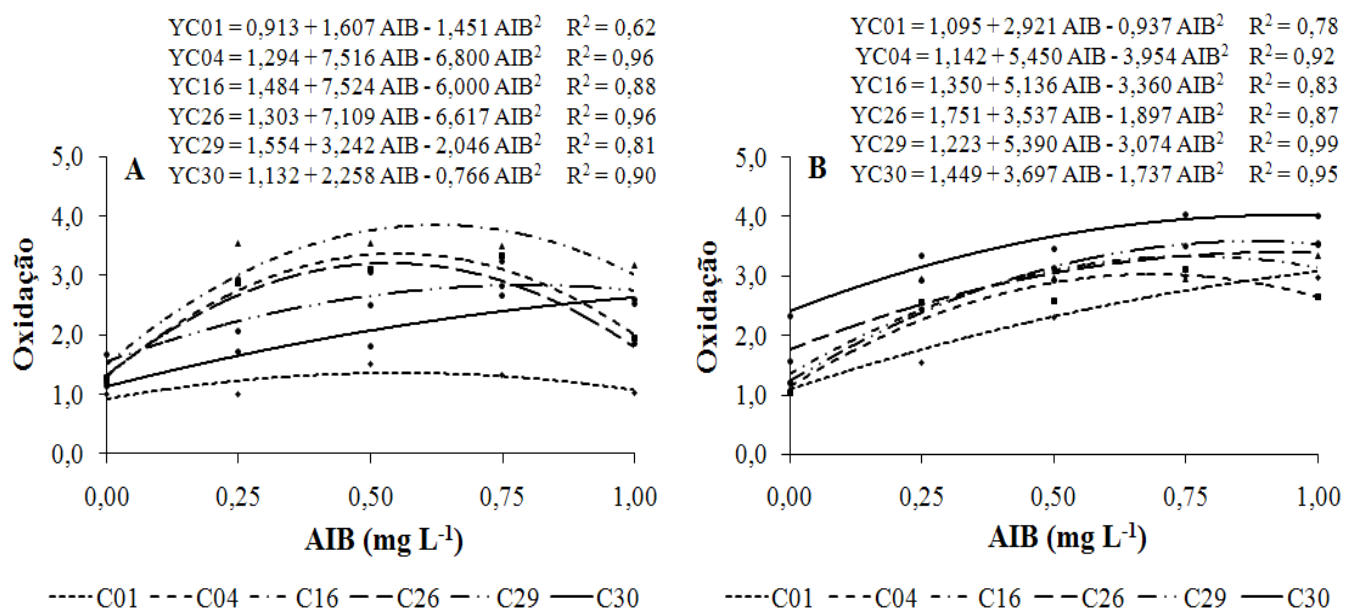

FIGURA 4: Oxidação das brotações de Eucalyptus urophylla x Eucalyptus globulus (C01, C04 e C16) e Eucalyptus grandis x Eucalyptus globulus (C26, C29 e C30), aos 35 dias após a inoculação, em função das doses de AIB aplicados aos meios de cultura MS (A) e JADS (B).

FIGURE 4: Oxidation of shoots of Eucalyptus urophylla x Eucalyptus globulus (C01, C04 and C16) and Eucalyptus grandis x Eucalyptus globulus (C26, C29 and C30), 35 days after inoculation in function of IBA concentrations applied in MS (A) and JADS (B) culture media.

A hiperidricidade em brotações micropropagadas pode ser ocasionada por uma série de fatores, dentre os quais o elevado conteúdo de citocininas e alteração da composição iônica do meio de cultura (KEVERS et al., 2004). Contudo, os tratamentos com diferentes concentrações de AIB não tiveram efeito proeminente sobre a hiperidricidade das brotações dos clones estudados. 

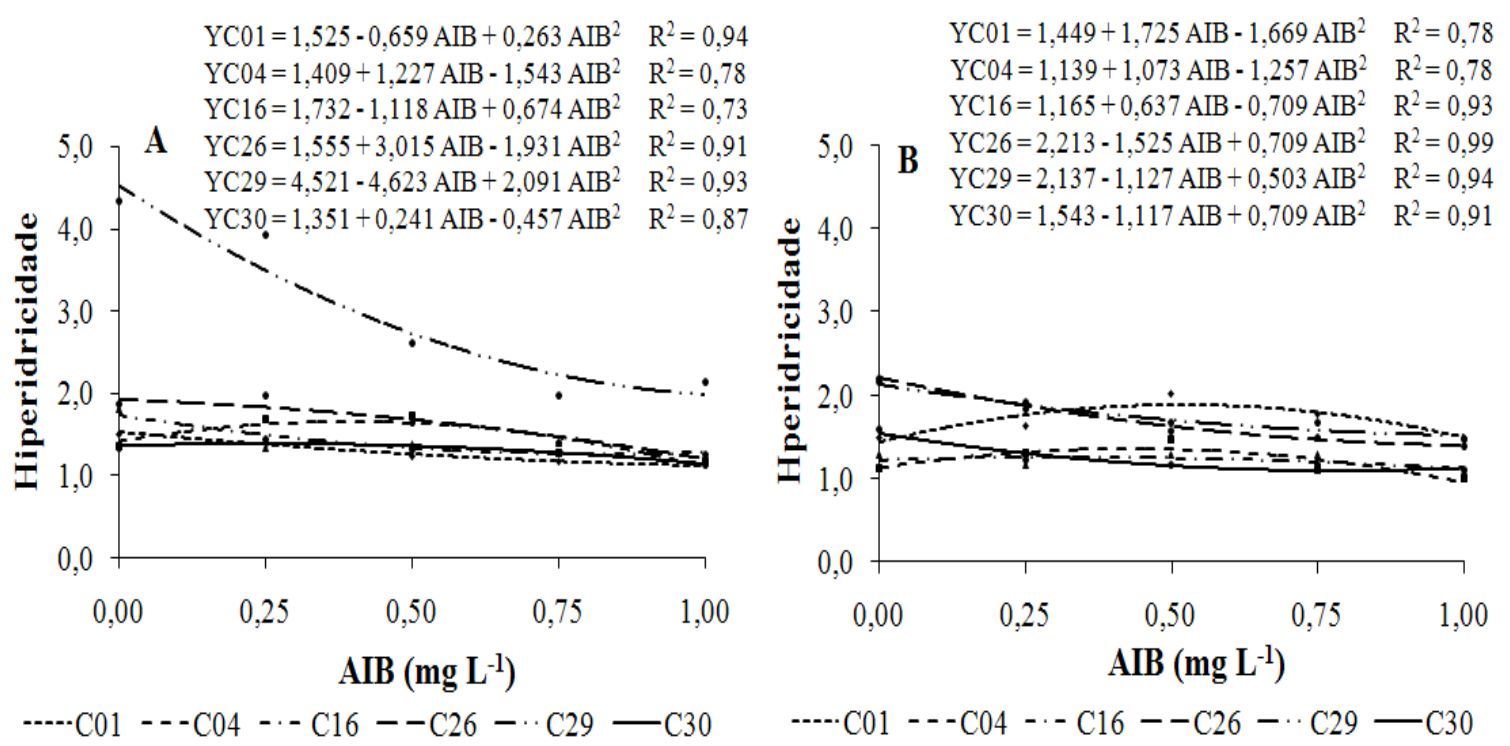

FIGURA 5: Hiper-hidricidade das brotações de Eucalyptus urophylla x Eucalyptus globulus (C01, C04 e C16) e Eucalyptus grandis x Eucalyptus globulus (C26, C29 e C30), aos 35 dias após a inoculação, em função das doses de AIB aplicados aos meios de cultura MS (A) e JADS (B).

FIGURE 5: Shoot hyperhydricity of Eucalyptus urophylla x Eucalyptus globulus (C01, C04 and C16) and Eucalyptus grandis x Eucalyptus globulus (C26, C29 and C30) clones, 35 days after inoculation in function of IBA concentrations applied in MS (A) and JADS (B) culture media.
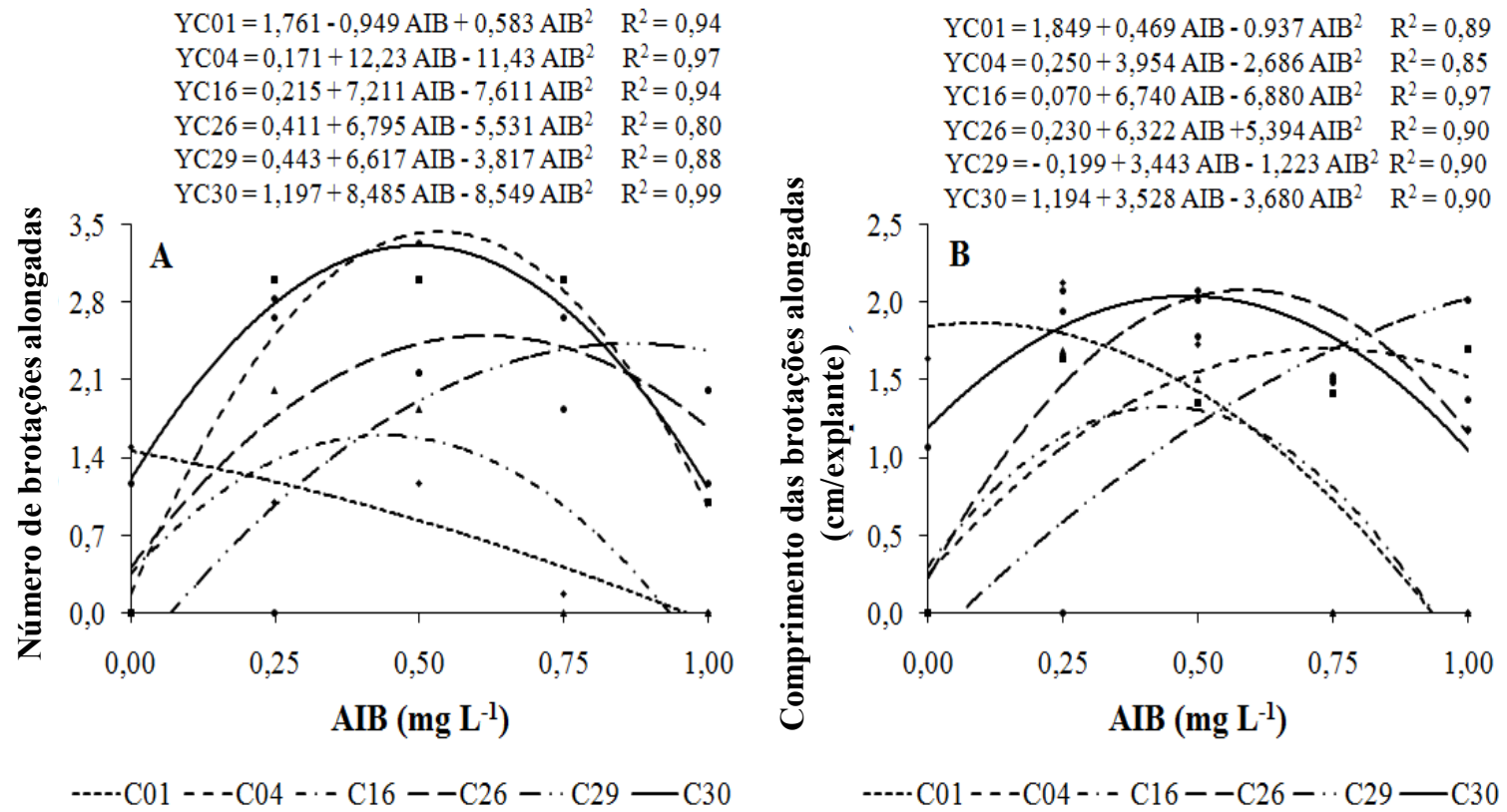

FIGURA 6: Número médio (A) e comprimento médio (B) das brotações alongadas por explante dos clones de Eucalyptus urophylla x Eucalyptus globulus (C01, C04 e C16) e Eucalyptus grandis x Eucalyptus globulus (C26, C29 e C30), aos 35 dias após a inoculação, em função das doses de AIB aplicados ao meio de cultura MS.

FIGURE 6: Mean number (A) and mean length (B) of elongated shoots per explant of Eucalyptus urophylla x Eucalyptus globulus (C01, C04 and C16) and Eucalyptus grandis x Eucalyptus globulus (C26, C29 and C30) clones, 35 days after inoculation in function of IBA concentrations applied in MS culture medium. 

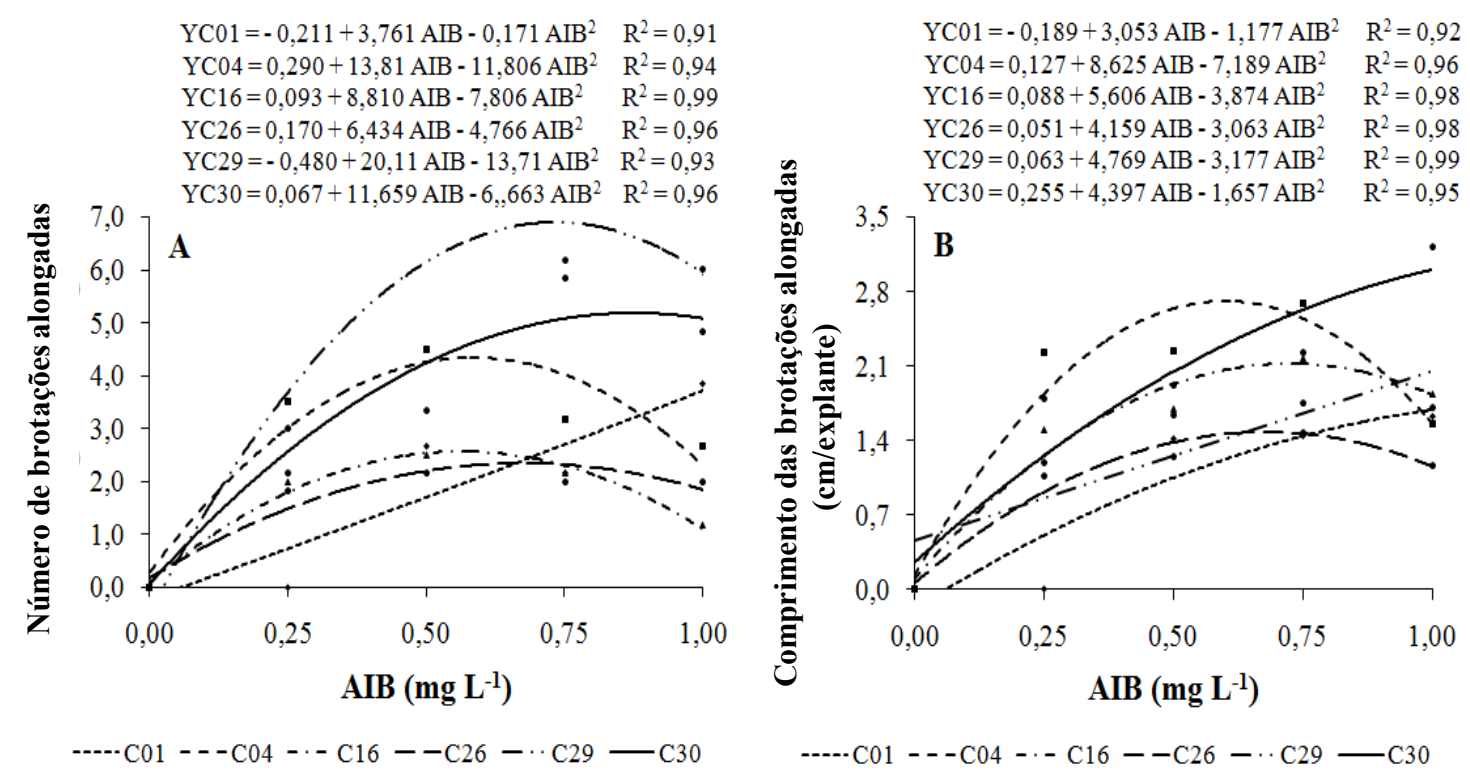

FIGURA 7: Número médio (A) e comprimento médio (B) de brotações alongadas por explante dos clones de Eucalyptus urophylla x Eucalyptus globulus (C01, C04 e C16) e Eucalyptus grandis x Eucalyptus globulus (C26, C29 e C30), em meio JADS, aos 35 dias após a inoculação, em função das doses de AIB aplicadas ao meio de cultura JADS.

FIGURE 7: Mean number (A) and mean shoot length (B) of elongated shoots per explant of Eucalyptus urophylla $\mathrm{x}$ Eucalyptus globulus (C01, C04 and C16) and Eucalyptus grandis $\mathrm{x}$ Eucalyptus globulus (C26, C29 and C30) clones, 35 days after inoculation in function of IBA treatments applied in JADS culture medium.

O clone C29 apresentou maiores valores médios de hiperidricidade em ambos meios de cultura em comparação aos demais clones (Tabela 3). As brotações hiperídricas caracterizaram-se pela hipertrofia dos tecidos foliares, espessamento da lâmina foliar, folhas encarquilhadas com aspecto translúcido, além do engrossamento excessivo dos caules das brotações. Esses sintomas denotam as sérias limitações que a hiperidricidade pode acarretar à sobrevivência ex vitro das brotações alongadas. Além disso, esse resultado reflete e reforça a especificidade de comportamento dos materiais genéticos quanto à micropropagação nos diferentes meios de cultura, e a necessidade de adequação das condições de cultivo in vitro para contornar esse problema.

Os clones não apresentaram respostas semelhantes quanto ao número e comprimento das brotações alongadas para as diferentes concentrações de AIB (Figuras 6 e 7). Os clones C04, C16, C26 e C30, no meio de cultura MS, apresentaram os valores máximos estimados para o número médio de brotações alongadas entre 0,47 e $0,61 \mathrm{mg} \mathrm{L}^{-1}$ de AIB, correspondendo a uma estimativa de $3,4,1,6,2,5$ e 3,3 brotos alongados por explante, respectivamente (Figura 6A). Esses resultados foram semelhantes ao observado por Brondani et al. (2009) no alongamento de Eucalyptus benthamii $x$ Eucalyptus dunnii em meio de cultura 1/2MS.

Por outro lado, os clones C01 e C29 apresentaram comportamentos diferentes aos dos demais clones no meio MS, sendo estimado maior número de brotações alongadas para o clone $\mathrm{C} 01$ em baixas concentrações de AIB, enquanto foi constatado o inverso para o clone C29 (Figura 6A).

Em relação ao comprimento das brotações alongadas em meio MS, os clones C01 e C29 apresentaram resultados divergentes aos observados para os demais clones. Enquanto para o clone C01 foi estimada a concentração de $0,25 \mathrm{mg} \mathrm{L}^{-1}$ de AIB como sendo a mais adequada para um bom alongamento, para o clone C29 esse valor foi de $1 \mathrm{mg} \mathrm{L}^{-1}$ (Figura 6B). Para os demais clones, as concentrações estimadas de AIB entre $0,48 \mathrm{e}$ $0,74 \mathrm{mg} \mathrm{L}^{-1}$ promoveram maior alongamento das gemas. As estimativas de comprimento das gemas alongadas foram de 1,7 cm para os clones $\mathrm{C} 04 \mathrm{e}$ C16 e de $2 \mathrm{~cm}$ para os clones C26, C29 e C30. Em meio MS, as concentrações de AIB, em torno de $1 \mathrm{mg} \mathrm{L}^{-1}$, promoveram a indução de calos na 
base dos explantes, que em seguida ocasionaram oxidação das brotações, comprometendo o efetivo alongamento desses explantes.

Os clones apresentaram comportamento diferenciado em relação aos tratamentos com AIB para o número e comprimento das brotações alongadas no meio de cultura JADS (Figura 7). De modo geral, ocorreu maior indução no alongamento das brotações dos clones C01, C29 e C30 quando foram subcultivadas em meio JADS comparativamente ao meio MS (Figuras 6A e 7A).

Os clones $\mathrm{C} 29$ e $\mathrm{C} 30$ apresentaram valores máximos estimados de 6,9 e 5,2 brotações alongadas por explante, no meio de cultura JADS, sendo esses valores bem superiores aos obtidos em meio MS. O meio JADS também foi utilizado no alongamento in vitro de Eucalyptus urophylla (SANTOS et al., 2004) e Grevillea robusta (SANTOS; WENDLING; GROSSI, 2004). Provavelmente, essa diferença deve-se à composição do meio de cultura JADS ser mais adequada ao alongamento dos clones híbridos de Eucalyptus grandis, explicando os resultados superiores para os clones C29 e C30. Além disso, o meio JADS possui uma composição nutricional definida para Eucalyptus grandis (CORREIA et al., 1995), o que pressupõe que tenha um balanço mineral mais próximo do adequado para a micropropagação de outras espécies do gênero.

A presença de AIB no meio de cultura suplementado com BAP favoreceu o alongamento das brotações dos clones do presente trabalho. De maneira semelhante, Santos et al. (2004) verificaram melhores resultados para alongamento in vitro de Eucalyptus urophylla utilizando $0,1 \mathrm{mg} \mathrm{L}^{-1}$ de AIB e $0,1 \mathrm{mg} \mathrm{L}^{-1}$ de BAP, após 30 dias de cultivo em meio de cultura JADS. Sotelo e Monza (2007) determinaram que o tratamento com $0,1 \mathrm{mg} \mathrm{L}^{-1}$ de BAP e $0,5 \mathrm{mg} \mathrm{L}^{-1}$ de AIB era a melhor combinação para promover o alongamento das brotações de Eucalyptus globulus sub. maidenii.Além disso, outras metodologias, como o uso de carvão ativado no meio de multiplicação, ou a permanência das culturas no escuro por alguns dias, podem contribuir para alongar brotações de Eucalyptus (CALDERÓN-BALTIERRA， 1994; SHARMA; RAMAMURTHY, 2000; GLOCKE et al., 2006).

Considerando o número de gemas alongadas dos clones em ambos os meios de cultura, os resultados demonstraram a eficiência do AIB no alongamento in vitro de clones de Eucalyptus urophylla x Eucalyptus globulus e de Eucalyptus grandis $\mathrm{x}$ Eucalyptus globulus provenientes de materiais adultos. Novos estudos buscando definir ajustes melhores e mais específicos são imprescindíveis para maximizar os resultados de micropropagação de híbridos de Eucalyptus globulus.

\section{CONCLUSÕES}

Os clones de Eucalyptus urophylla $\mathrm{x}$ Eucalyptus globulus e Eucalyptus grandis $\mathrm{x}$ Eucalyptus globulus apresentaram diferenças quanto ao número de tufos de brotações produzidos em 25 subcultivos sucessivos, com taxa de multiplicação média de 3,0 brotações em cada subcultivo.

No alongamento in vitro, o meio de cultura JADS foi mais adequado para obtenção de brotações alongadas dos materiais genéticos. Por sua vez, os clones responderam de maneira específica às diferentes concentrações de AIB utilizadas no presente estudo. $\mathrm{O}$ intervalo médio entre $0,40 \mathrm{e}$ $0,80 \mathrm{mg} \mathrm{L}^{-1}$ de AIB proporcionou o maior número e comprimento das brotações alongadas in vitro e com melhor vigor.

\section{REFERÊNCIAS}

AGGARWAL, D. et al. Factors affecting micropropagation and acclimatization of an elite clone of Eucalyptus tereticornis Sm. In vitro Cellular Development and Biology-Plant, Washington, v. 48, p. 521-529, 2012.

ALVES, E. C.; XAVIER, A.; OTONI, W. C. In vitro regeneration from stem explants of Eucalyptus grandis $\mathrm{x}$ E. urophylla clones through organogenesis. Revista Árvore, Viçosa, v. 28, p. 643-653, 2004.

ANDRADE, W. F.; ALMEIDA, M.; GONÇALVES, A. N. Multiplicação in vitro de Eucalyptus grandis sob estímulo com benzilaminopurina. Pesquisa Agropecuária Brasileira, Brasília, v. 41, n. 12, p. 1715-1719, 2006.

ARYA, I. D. et al. Micropropagation of superior Eucalyptus hybrids FRI-5 (Eucalyptus camaldulensis Dehn x E. tereticornis Sm) and FRI14 (Eucalyptus torelliana F. V. Muell x E. citriodora Hook): a commercial multiplication and field evaluation. African Journal of Biotechnology, Nairobi, v. 8, n. 21, p. 5718-5726, 2009.

BENNETT, I. J. et al. Alternating cytokinins in multiplication media stimulates in vitro shoot growth and rooting of Eucalyptus globulus Labill. Annals of Botany, Oxford, v. 74, p. 53-58, 1994. BENNETT, I. J.; MCDAVID, D. A. J.; MCCOMB, J. $\mathrm{A}$. The influence of amonium nitrate, $\mathrm{pH}$ and indole 
butyric acid on root induction and survival in soil of micropropagated Eucalyptus globulus. Biologia Plantarum, Praga, v. 47, p. 355-360, 2003.

BILLARD, C. E.; LALLANA, V. H. Multiplicación in vitro de Eucalyptus dunnii. Ciencia, Docencia y Tecnología, Entre Ríos, n. 30, p. 199-216, 2005. BORGES, S. R. et al. Enraizamento de miniestacas de clones híbridos de Eucalyptus globulus. Revista Árvore, Viçosa, v. 35, n. 3, p. 245-434, 2011.

BRAVO, C. D. V. et al. Controle genético da regeneração in vitro em progênies de Eucalyptus grandis. Ciência Rural, Santa Maria, v. 38, n. 8, p. 2181-2185, 2008.

BRONDANI, G. E. et al. Estabelecimento, multiplicação e alongamento in vitro de Eucalyptus benthamii Maiden \& Cambage x Eucalyptus dunnii Maiden. Revista Árvore, Viçosa, n. 33, v. 1, p. 1119, 2009.

BRONDANI, G. E. et al. Micropropagation of Eucalyptus benthamii to form a clonal microgarden. In vitro Cellular and Developmental Biology-Plant, Columbia, v. 48, n. 5, p. 478-487, 2012.

CALDERÓN-BALTIERRA, X. V. Influencia del cálcio y ácido giberélico en el alargamiento de brotes adventícios in vitro de Eucalyptus globulus. Bosque, Valdívia, v. 15, n. 1, p. 33-38, 1994.

CHALUPA, V. C. In vitro propagation of mature trees of Sorbus aucuparia L. and field performance of micropropagated trees. Journal of Forest Science, Praga, v. 48, n. 12, p. 529-535, 2002.

CORREIA, D. et al. Efeito do meio de cultura líquido e sólido no crescimento e desenvolvimento de gemas de Eucalyptus grandis x Eucalyptus urophylla na multiplicação in vitro. IPEF, Piracicaba, v. 48-49, p. 107-116, 1995.

DEL PONTE, E. M. et al. Multiplicação e enraizamento in vitro de Eucalyptus globulus subsp. globulus Labill. Revista Árvore, Viçosa, v. 25, n. 1, p. 1-8, 2001.

GAMBORG, O. L.; MILLER, R. A.; OJIMA, K. Nutrient requirements of suspension cultures of soybean root cells. Experimental Cell Research, Burlington, v. 50, p. 151-158, 1968.

GEORGE, E. F. Plant tissue culture procedure Background. In: GEORGE, E. F.; HALL, A. M.; DE KLERK, G.-J. (Eds.). Plant propagation by tissue culture: the background. 3. ed. Dordrecht: Springer, 2008. v. 1, p. 1-28.

GLOCKE, P.; COLliNS, G.; SEDGLEY, M. Effects of auxins on organogenesis and somatic embryogenesis from juvenile explants of Eucalyptus erythronema, E. stricklandii, and two inter-specific hybrids. Journal of Horticultural Science and Biotechnology, Dundee, v. 81, n. 6, p. 1009-1014, 2006.

GLOCKE, P. et al. Micropropagation of juvenile tissue of Eucalyptus erythronema x Eucalyptus stricklandii cv. 'Urrbrae Gem'. In Vitro Cellular and Developmental Biology-Plant, Washington, v. 42, p. 139-143, 2006.

GOMES, F.; CANHOTO, J. M. Micropropagation of Eucalyptus nitens Maiden (shining gum). In Vitro Cellular and Developmental Biology-Plant, Washington, v. 39, p. 316-321, 2003.

GOMÉZ, C.; RÍOS, D.; SÁNCHEZ-OLATE, M. Efecto del subcultivo sucesivo sobre la caulogénesis adventícia de Eucalyptus globulus. Bosque, Valdívia, v. 28, n. 1, p. 13-17, 2007.

GOODGER, J. Q. D. et al. Micropropagation of Eucalyptus polybractea selected for key essential oil traits. Functional Plant Biology, Melbourne, v. 35, p. 247-251, 2008.

GRATTAPAGLIA, D.; MACHADO, M. A. Micropropagação. In: TORRES, A. C.; CALDAS, L. S.; BUSO, J. A. (Eds.). Cultura de tecidos e transformação genética de plantas. Brasília: EMBRAPA-SPI/EMBRAPA-CNPH， 1998. v.1, p.183-260.

HACKETT, W. P. Juvenility and maturity. In: BONGA, J. M.; DURZAN, D. J. (Eds.). Cell and tissue culture in forestry. Dordrecht: Kluwer Academic Publishers, 1987.

JOSHI, I. et al. In vitro clonal propagation of mature Eucalyptus F1 hybrid (Eucalyptus tereticornis Sm. $\mathrm{x}$ E. grandis Hill ex. Maiden). Silvae Genetica, Frankfurt, v. 52, n. 3-4, p. 110-113, 2003.

KEVERS, C. et al. Hyperhydricity of micropropagated shoots: atypically stress-inuced change of physiological state. PlantCell, Tissue and Organ Culture, Dordrechet, v.77, p. 181-191, 2004.

LIMA, M. M.; GONÇALVES, A. N. Efeito do Thidiazuron na multiplicação in vitro de gemas de um clone de Eucalyptus grandis x Eucalyptus tereticornis. Scientia Forestalis, Piracicaba, n. 53, p. 49-56, 1998.

LLOYD, G.; MCCOWN, B. Commercially feasible micropropagation of mountain laurel, Kalmia latifolia, by use of shoot tip culture. Combined Proceedings of the International Plant Propagator's Society, v. 30, p. 421-327, 1981.

MANKESSI, F. et al. In vitro rooting of genetically related Eucalyptus urophylla $\times$ Eucalyptus grandis 
clones in relation to the time spent in culture. Trees, Berlin, v. 23, n. 5, p. 931-940, 2009.

MURASHIGE, T.; SKOOG, F. A revised medium for rapid growth and bio assays with tobacco tissue cultures. Physiologia Plantarum, Copenhagen, v. 15, p. 473-497, 1962.

NOURISSIER, S.; MONTEUUIS, O. In vitro rooting of two Eucalyptus urophylla x Eucalyptus grandis mature clones. In Vitro Cellular and Developmental Biology-Plant, Washington, v. 44, p. 263-272, 2008.

NUGENT, G. et al. Adventitious bud induction in Eucalyptus globulus Labill. In Vitro Cellular and Developmental Biology-Plant, Washington, v. 37, p. 388-391, 2001.

PIERIK, R. L. M. Rejuvenation and micropropagation. In: INTERNATIONAL CONGRESS ON PLANT TISSUE AND CELL CULTURE, 7., 1990, Amsterdam. Proceedings... Dordrecht: Kluwer Academic Publishers, 1990, p. 91-101.

PINTO, G. et al. Factors influencing somatic embryogenesis induction in Eucalyptus globulus Labill.: basal medium and anti-browning agents. Plant Cell, Tissue and Organ Culture, Dordrecht, v. 95, n. 1, p. 79-88, 2008.

QUOIRIN, M.; LEPOIVRE, P. Étude de milieux adaptes aux cultures in vitro de Prunus. Acta Horticulturae, Wageningen, v.78, p. 437-442, 1977.

RIBEIRO, J. M. et al. Efeito do melado de canade-açúcar no desenvolvimento in vitro de bananeira (Musa spp.) cv. Maçã. Revista Ceres, Viçosa, v. 59, n. 3, p. 293-298, 2012.

SANTOS, D. C. et al. Alongamento in vitro de Eucalyptus urophylla. Colombo: CNPF/ EMBRAPA, 2004. (Comunicado Técnico, 120).

SANTOS, D. C.; WENDLING, I.; GROSSI, F. Efeito de diferentes combinações de fitorreguladores e vitaminas no desenvolvimento in vitro e ex vitro de Grevillea robusta Cunn. Colombo: CNPF/ EMBRAPA, 2004. (Comunicado Técnico, 112).

SHARMA, S. K.; RAMAMURTHY, V. Micropropagation of 4-year-old elite Eucalyptus tereticornis trees. Plant Cell Reports, Berlin, v. 19, p. 511-518, 2000.

SOTELO, M.; MONZA, J. Micropropagation of Eucalyptus maidenii elite trees. Agrociencia, Montevideo, v. 9, n. 1, p. 81-89, 2007.

TRINDADE, H.; PAIS, M. S. In vitro studies on Eucalyptus globulus rooting ability. In Vitro Cellular and Developmental Biology Plant, Washington, v. 33, p. 1-5, 1997.

VON ADERKAS, P.; BONGA, J. M. Influencing micropropagation and somatic embryogenesis in mature trees by manipulation of phase change, stress and culture environment. Tree Physiology, Victoria, v. 20, p. 921-928, 2000.

WARRAG, E. I.; LESNEY, M. S.; ROCKWOOD, D. L. Micropropagation of field tested superior Eucalyptus grandis hybrids. New Forests, Rotorua, v. 4, p. 67-79, 1990.

XAVIER, A.; WENDLING, I.; SILVA, R. L. Silvicultura clonal: princípios e técnicas. Viçosa: UFV, 2009. 